\title{
Vergara, Martha (2017). La práctica cotidiana de los profesores. Un estudio desde el proceso de formación en el posgrado. México, Universidad de Guadalajara/Universidad de Oviedo/Universidad Autónoma de Zacatecas.
}

\author{
GUADALUPE OLIVIER* \\ Universidad Pedagógica Nacional - México \\ Recibido el 10-08-18, aprobado el 14-08-18
}

Aun cuando uno de los temas centrales en los procesos educativos es el relativo a la práctica del profesorado (Gómez López, 2008; García Cabrero, Loredo Enríquez y Carranza Peńa, 2008; Cańedo Ortíz y Figueroa Rubalcava, 2013, entre otros), son escasos los trabajos que se plantean desde la experiencia de docentes en proceso de formación en el posgrado. El contexto de la reflexión del profesorado frente a su quehacer cotidiano ha tendido a plantearse en el propio contexto de su ejecución en las escuelas de los distintos niveles educativos. Es por ello que una de las aportaciones del texto radica en presentar las tensiones, auto reflexiones y cambios posibles en las prácticas cotidianas que se generan en los docentes, a partir de la experiencia de formación en el programa de posgrado.

Ante ello, surgen las preguntas, ¿cómo pensar y cómo pensarse en la práctica docente? ¿cómo aludir, incluso, a los propios procesos de intervención de los formadores de docentes en los espacios de debate en el posgrado? Con esto, podría decirse que, en el ámbito del estudio que se presenta en el libro, la práctica docente también remite, implícitamente, a la relación íntima entre los estudiantes docentes y el profesorado del posgrado que orienta la forma teórica, así como reflexiva, de entender la práctica docente. En tal sentido, el texto se introduce con una revisión profunda sobre su debate teórico.

\footnotetext{
* Socióloga. Maestra y doctora en Pedagogía por la UNAM. Especialista en política de la educación y educación superior. Profesora-investigadora de la Universidad Pedagógica Nacional (UPN) y del Colegio de Pedagogía de la Facultad de Filosofía y Letras de la UNAM. Miembro del Sistema Nacional de Investigadores-CONACYT. Pertenece al Comité Directivo del Consejo Mexicano de Investigación Educativa (COMIE) y de la Red Mexicana de Estudios de los Movimientos Sociales, A.C. Actualmente coordina el Doctorado en Política de los Procesos Socioeducativos en la UPN. Correo: mariao969@yahoo.com.mx
} 
Como primer aspecto habría que reconocer la existencia no de una sino de múltiples docencias. De manera que la noción de la docencia y su práctica cotidiana no es un proceso unívoco ni general, sino que, de manera contraria, las prácticas de la docencia se constituyen en función de los distintos contextos y especificidades de los subsistemas o niveles educativos, a partir de su vinculación con los trayectos personales, con las diversas circunstancias de la tradición institucional y frente a la emergencia de problemas socioeducativos complejos.

En este mismo sentido, tendría que establecerse el paso de la idea de práctica a una noción también más plural, es decir, de "prácticas». Es, en ese caso, una confluencia ineludible que articula lo prescrito, tanto a nivel institucional como teórico-pedagógico, con lo impredecible en el nivel de la subjetividad concreta del docente y estudiante, y luego los procesos de subjetivación en la relación de ambos que permitirían comprender las prácticas docentes, en tanto prácticas educativas (Pérez Ornelas, 2016).

Así, la práctica docente, como bien se enfatiza en el libro, no podría ser una ejecución obediente de una teoría o de una ordenación. Por ello, es importante reconocer el sentido de la subjetividad, como parte intrínseca del proceso educativo, donde entra en acción el docente, la prescripción institucional y también las intersubjetividades del estudiantado. Entenderlo de esta manera puede remitir a las formas que adquiere la relación escolar, como lo han señalado ya los clásicos de la sociología del currículum, como Apple (2008) o Torres (2005), en las tres de dimensiones clave para analizar el currículum desde una lógica sociopolítica:

1) Lo institucional u oficial, aquello que está dado explícitamente

2) Lo permeado por la ideología, la cultura y las relaciones de dominio hegemónico no explícito, o, en otras palabras, lo oculto

3) Lo cotidiano, lo que se «usa», las prácticas cotidianas en el aula, donde entra en juego la trayectoria personal que, al confluir intersubjetivamente con los otros sujetos, se convierte en una fuerza educativa nodal

Estas tres dimensiones, desde luego, no solo son estancos aislados, sino que confluyen permanentemente en un telón de fondo contextual, social e histórico, pero también político mediado por relaciones de fuerza, por la lucha entre los saberes legítimos y los prácticos que saltan de las realidades concretas. Son, a la larga, parte de procesos educativos que, lejos de ser desdeñados, merecen ser reconocidos e incluso potencializados como detonadores de aprendizaje.

Desde luego, esto permite pensar en una relación de subjetividad-intersubjetividad, como lo señala José Antonio Méndez Sanz en uno de los prólogos del libro de Vergara (2017). Esta relación implica tomarnos muy en serio la comprensión de la elaboración de significados y representaciones sociales, 
así como la interacción con la cultura que se constituye de un entramado por demás complejo, de los lugares, vivencias, experiencias de los trayectos de vida y, también, de cómo se nutre e interactúa con la diversidad de «las culturas» concretas, de los espacios de acción educativa, de los espacios áulicos, de las relaciones institucionales y del propio espacio societal-comunitario de donde emerge y se nutre, donde lo que presenciamos son flujos continuos de intercambio y aprendizajes, que, casi implícitamente, construyen estructuras socio-institucionales propias.

A fin de cuentas, todo esto es un intercambio de experiencias históricas en la medida que se construyen en el tiempo, que confluyen y dan identidad recíproca. Son, por lo tanto, constitutivos y constituyentes del espacio de aquello que se define o circunscribe como prácticas docentes. En tal sentido, la práctica o más bien prácticas, no son ineludibles ni pueden desmontarse de su realidad histórica, es decir, del ámbito específico de la cultura individual e institucional y del conjunto de los motivantes intersubjetivos.

En el tiempo, esto va constituyendo, a nivel cognitivo, formas de hacer la docencia y formas de hacer que se dé la docencia. Cobra relevancia, por lo tanto, el estudio de los significados, las representaciones, los imaginarios y todo aquello que tiene lugar en la escena educativa.

Y, en esta perspectiva, ¿cuál es el papel de los programas de formación de formadores?, ¿hasta dónde llega la prescripción teórica y en qué momento penetra la relación intersubjetiva que se convierte en un todo acumulado y re-significado en el conjunto de prácticas?, ¿`cuáles son los puntos de inflexión, los aspectos críticos, pero también los alcances de la relación entre acción y significado?

El texto de Vergara coloca al centro estos y muchos más cuestionamientos por demás relevantes. La profundización teórica y la articulación con los sujetos de investigación nos revelan, invariablemente, el sentido complejo de las interactuaciones educativas en el entorno de la complejidad y de la no linealidad. En este sentido, ¿qué implican las prácticas docentes, en el trayecto de vida de un estudiante? ¿cuál es el reto de intercomunicación entre saberes teóricos ante hechos concretos de la también complejidad de los contextos sociales y retos de enseñanza?, ¿cómo distinguir los múltiples escenarios donde se ejecutan las prácticas y cómo definir, tanto como decidir, cuál es la «mejor» práctica?

En este libro se desarrolla el análisis de la significación compleja de estudiantes de la maestría en Educación con Intervención en Práctica Educativa del Centro de Estudios de Posgrado de la Secretaría de Educación del Estado de Jalisco. Se plantea la percepción sobre la influencia de sus estudios de posgrado en sus prácticas docentes, de educación primaria fundamentalmente, frente a 
las prácticas reales, es decir, las ejecutadas, las de la cotidianidad escolar, aquellas que Michael Apple (2008) señala como las elaboradas en el Currículum en uso, permeadas de experiencias, cultura e ideología que se nutren del presente, pero que también incorporan fuertemente historias del pasado. Aquellas que han prevalecido en la tradición educativa, que son vivencias del proceso recuperadas de la memoria individual, incluso del momento formativo de la infancia que se nutre, además, de una relación permanente y compleja entre el ser y el deber ser. De todo aquello que puede develar el conflicto interno entre el docente que soy y quien puedo ser, de ahí también se devela su dimensión psicoanalítica.

Estos aspectos son de especial relevancia pues una de las tendencias en la investigación educativa, hasta hace poco, fue que los estudios de tipo cualitativo, aún centrados en los sujetos, eran re-pensados, o re-significados desde el postulado teórico y la interpretación densa del investigador. Las mediaciones que recientemente se han incorporado plantean un relato analítico-descriptivo donde la palabra de los sujetos pretende no ser tergiversada por la carga cognitiva del investigador. Y, aunque reconocemos la dificultad de la "pureza», cuestión que tampoco es el propósito de los investigadores, reconozco en el trabajo de Vergara una honestidad investigativa destacable que pretende ubicar el problema en su justo contexto y dando una valía inconmensurable a los sujetos.

En la elección de estos, por demás pertinente para el cumplimiento de los objetivos de la investigación, se destaca, en una de sus características, que, además de que fuesen docentes de educación primaria, también su formación proviene de la educación normal, y que su docencia se realizara dentro de los marcos de contrastación entre la escuela rural y la urbana.

Uno de los retos futuros de esta investigación versaría en que, frente a los retos que impone la reforma educativa vigente en México $^{1}$, se hiciera una comparación de los resultados de este estudio frente a las prácticas cotidianas de docentes que no se formaron en la escuela normal, lo cual sería sumamente interesante para abonar en la noción de la pluralidad del significante práctica docente, frente a procesos de formación diferenciados.

Y, en este mismo tenor, otra de las aportaciones del texto es que la estructura metodológica de la investigación puede permitir ser aplicada a docentes de otros niveles de formación, como, por ejemplo, en el ámbito universitario

\footnotetext{
1 La reforma educativa vigente en México, da la posibilidad de que ingresen al servicio profesional docente, personas que no fueron formadas en las Escuelas Normales. Como sabemos, estas instituciones históricamente fueron las encargadas de formar a maestros de escuela. Con la Reforma Educativa aprobada en el ańo de 2012, el perfil se abre a cualquier profesional que apruebe el examen de ingreso para ocupar un puesto de maestro.
} 
y de la educación media superior donde la complejidad del proceso docente es muy amplio y poco estudiado.

No obstante que en la formación del profesorado de educación básica existe toda una instrumentación didáctico-pedagógica, como una de sus tareas fundamentales, uno de los hallazgos que se presentan en el libro es que no está claramente identificada y heterogéneamente definida por los docentes. Y, en este sentido, vale reflexionar que mucho menos lo está para los docentes de niveles educativos donde no es obligada una formación docente previa, como en la educación media superior y superior. Esto implicaría identificar la pluralidad de significados y las formas de ejecución de las prácticas.

Por otra parte, se destaca, entre los hallazgos de Martha Vergara, que hay una tendencia importante en los sujetos estudiados a definir la práctica docente en función de "cómo le gustaría que le enseñaran». Esto es básico pues la relación con la dimensión subjetiva es intrínseca al proceso y permeable en la interpretación del deber ser.

Asimismo, otro aspecto destacable es el relativo a cómo se interconecta la interpretación de la práctica al campo de las emociones. Este factor es muy relevante y necesario subrayar, pues el mundo de los significados no puede desligarse del campo emocional, aunque muy pocas veces es tratado como componente de incidencia primaria en la configuración de las prácticas educativas en su conjunto. Este aspecto, que Juan Casassus (2008) denomina como realidad emocional, es, probablemente, el hilo con el que se bordan las interpretaciones y se definen las acciones que, por un lado, predisponen las prácticas docentes, pero que también se ponen en juego para actuar frente a lo impredecible, en la emergencia de los retos cotidianos.

Un ejemplo de ello es cómo los docentes se sienten agobiados por las demandas formales que les exige la institución y que perciben como entorpecedores de su vida privada. El grado de insatisfacción, frente a la presión institucional, se traduce en una loza que puede predisponer actitudes respecto a sus acciones hacia sus estudiantes, lo que genera ambientes emocionales adversos. Aquí nos encontramos frente a un proceso distinto en el cual el profesorado tiene que dar respuesta al trabajo docente.

Si los significados son los ejes de su práctica, la percepción sobre su trabajo, aquel que se remunera, el que está en el marco de normas laborales, el que es sometido permanentemente a escrutinio, necesariamente tiene que repercutir en sus emociones, pues predispone ritualizaciones que complejizan su práctica, que limitan la creatividad, que direccionan su papel docente a través de procesos vistos como deberes inamovibles y, en síntesis, poco satisfactorios. 
En tal sentido, el punto crítico emocional que se presenta no es el hecho mismo de la docencia, sino de las prescripciones laborales que giran alrededor de ella, que, además, se encuentran identificadas como espacios ocupacionales mal pagados y poco reconocidos socialmente. Sin embargo, también dentro de ello, existen factores de entusiasmo y motivación. Uno de estos es, justamente, el caso de la pertenencia al programa de posgrado. La motivación inicial es la movilidad social, tal como se afirma en los casos estudiados.

La exigencia institucional, nuevamente, se erige como un eje motor; sin embargo, luego, hay desplazamientos que dan sentido para el aprendizaje y cambio en sus prácticas docentes, reconocidas por sí mismos.

El estudio de las prácticas cotidianas de los docentes, en todo caso, no solo se acota a la comprensión de los procesos de enseńanza y aprendizaje, permite develar otro tipo de anclajes sociales que pueden explicar contextos educativos mediados por dimensiones más amplias de lo cultural, político y económico. Permite, asimismo, dimensionar la complejidad educativa y rebasar un enfoque meramente rígido y prescriptivo. El texto de Martha Vergara, en suma, nos deja varios caminos para la profundización del tema en este sentido, que es necesario revisar.

\section{REFERENCIAS BIBLIOGRÁFICAS}

Apple, M. (2008). Ideología y curriculo. 3a ed. Madrid: Akal.

Casassus, J. (2008). Aprendizajes, emociones y clima de aula. Paulo Freire. Revista de Pedagogía Crítica, 7(6), diciembre, 81-97.

Cañedo Ortiz, T.J, y Figueroa Rubalcava, A.E. (2013). La práctica docente en educación superior: una mirada hacia su complejidad. Sinéctica, (41), 2-18. Recuperado el 1 de abril de 2018, de http://www.scielo.org.mx/ scielo.php?script=sci_arttext\&pid=S1665-109X2013000200004\&lng=es \&tlng=es.

García Cabrero,B., Loredo Enríquez, J. y Carranza Peña, G. (2008). Análisis de la práctica educativa de los docentes: pensamiento, interacción y reflexión. Revista electrónica de investigación educativa, 10(spe), 1-15. Recuperado el 25 de marzo de 2018, de http://www.scielo.org.mx/scielo. php?script=sci_arttext\&pid=S1607-40412008000300006\&lng=es\&tln $\mathrm{g}=\mathrm{es}$.

Gómez López, L.F. (2008). Los determinantes de la práctica educativa. Universidades [en línea], (Julio-Septiembre). Recuperado el 29 de marzo de 2018, de http://www.redalyc.org/articulo.oa?id=37303804 
Pérez Ornelas, M.I. (2016). Las prácticas educativa y docente en un grupo de profesores universitarios. Revista Latinoamericana de Estudios Educativos (México) [en linea] 2016, XLVI. Recuperado el 29 de julio de 2018, de <http://www.redalyc.org/articulo.oa?id=27046182005> ISSN 0185-1284

Torres, J. (2005). El currículum oculto. 8a . ed. Madrid: Morata.

Vergara Fregoso, M. (2017). La práctica cotidiana de los profesores. Un estudio desde el proceso de formación en el posgrado. México, Universidad de Guadalajara/ Universidad de Oviedo/Universidad Autónoma de Zacatecas. 